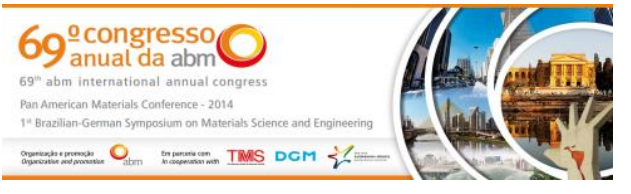

Tema: Corrosão

\title{
MÉTODO PARA DETERMINAÇÃO DE FAIXAS DE PARÂMETROS IDEAIS DE PROCESSAMENTO DE PINTURA CATAFORÉTICA*
}

\section{Resumo}

Egnalda Pereira da Silva Pimenta ${ }^{1}$ José Geraldo Moreira²

Visando a redução de custos e peso dos veículos, uma grande variedade de materiais, metálicos ou não, tem sido utilizada na produção de carrocerias. Cada um desses materiais possui uma tensão crítica de aplicação da tinta cataforética (tensão de ruptura) e, como a carroceria é pintada integralmente, a homogeneidade da pintura final em todas as partes representa um fator de grande relevância. Geralmente a tensão de aplicação da tinta é determinada em função do tempo disponível e não considera o tipo de tinta empregada, o que, em muitos casos, restringe o emprego de certos substratos metálicos. Por isso, o estabelecimento de janelas de processamento para a pintura dos materiais permite uma maior flexibilidade operacional. Assim, para esse estudo, foram pintados, em linha de pintura piloto, corpos de prova de aços, com e sem revestimento de zinco, utilizando-se três tipos de tintas e variando-se as tensões e os tempos para sua deposição, de modo a estabelecer uma "janela de processamento" para cada aço em função do tipo de tinta empregada. As "janelas de processamento" conferem maior flexibilidade aos processos de pintura, além de ser uma maneira conveniente de selecionar a tinta de melhor desempenho para uma determinada linha.

Palavras-chave: Pintura cataforética; Tensão de ruptura; Defeitos na pintura cataforérica.

\section{METHOD FOR DETERMINATION OF IDEAL PARAMETERS OF PROCESSING CATAPHORETIC PAINTING}

\section{Abstract}

In order to reduce the costs and weight of vehicles, a great variety of materials, metallic or not, has been used in car body production. Each material has a specific critical voltage for cataphoretic paint application (rupture voltage), and taking in account that all them are painted simultaneously, it is very important achieve a homogenous final painting in the whole car. Usually, the paint application voltage is determined by the available time, and does not consider the paint's type, which, in many cases, restricts the use of certain metallic substrates. Therefore, the establishment of "processing windows" for painting dissimilar material at the same time allows more operational flexibility. In this work, samples of steels, galvanized or not, were painted in a pilot line using three types of paints and varying application voltage and time, so that it was possible to establish a "processing window" for each steel depending on the paint used. The "processing windows" provide greater flexibility to the processes of painting, besides being a convenient way to select the best paint performance for a specific line.

Keywords: Cataphoretic painting; Rupture voltage; Cataphoretic painting' defects.

1 Engenheira Química, M.Sc, Gerência Geral de Pesquisa e Desenvolvimento da Usiminas, Ipatinga, MG, Brasil.

2 Técnico em Química, Gerência Geral de Pesquisa e Desenvolvimento da Usiminas, Ipatinga, MG, Brasil.

\footnotetext{
* Contribuição técnica ao $69^{\circ}$ Congresso Anual da ABM - Internacional e ao 14ํㅡㄹ ENEMET - Encontro Nacional de Estudantes de Engenharia Metalúrgica, de Materiais e de Minas, 21 a 25 de julho de 2014, São Paulo, SP, Brasil.
} 


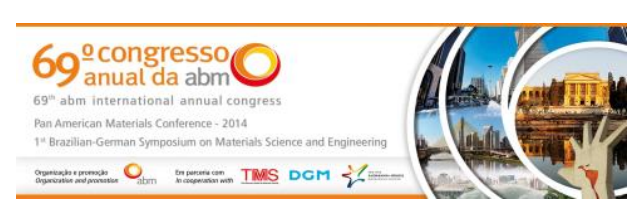

\section{INTRODUÇÃO}

A exigência do mercado consumidor por automóveis com melhor resistência à corrosão tornou-se uma constante fonte de preocupação por parte das montadoras. Sabe-se que a corrosão em carrocerias ocorre, na maioria das vezes, na sua parte inferior e em espaços vazios e uniões. Os procedimentos para aumentar à resistência a corrosão são os mais diversos e complementares, como modificações de projeto para evitar acúmulo de eletrólitos e a formação de pilhas galvânicas, o emprego de ceras e, principalmente, o uso de aços revestidos e de pintura.

Os revestimentos das chapas de aço podem ser de vários tipos, tais como, eletrolíticos (Zn, Zn-Fe e Zn-Ni) ou por imersão a quente (Zn, Zn-Al, Zn-Fe e Al). Entre as pinturas, o padrão adotado por cerca de $98 \%$ da indústria automobilística mundial é a eletrodeposição cataforética, em razão da sua facilidade operacional, baixo custo, alto poder de penetração nas partes ocas das peças, produtividade, ótima resistência à corrosão e, também, por não agredir o meio ambiente (tem 99\% de reaproveitamento) [1,2].

O princípio fundamental da pintura cataforética é a atração de cargas elétricas opostas. Assim, a peça a ser pintada nesse processo é o catodo do circuito e é imersa em um banho de tinta com formulação especial (80 a 90\% de sólidos, 1 a 3\% de solventes orgânicos voláteis e água deionizada) que permite a sua polarização. Durante o processo de pintura ocorrem simultaneamente quatro fenômenos básicos da eletroquímica: eletroforese; hidrólise da água, eletro-osmose e eletrodeposição. $\mathrm{Na}$ eletroforese as partículas da tinta migram, sob a influência de um campo elétrico gerado por uma diferença de potencial, para a peça e nela aderem, expulsando a água num processo denominado eletro-osmose. A precipitação das partículas de tinta na peça forma a camada eletrodepositada. A hidrólise da água, ou eletrólise, é o fenômeno de reação de oxi-redução da água com a formação de hidrogênio e oxigênio nos eletrodos conforme as seguintes reações [3,4].

No anodo:

$$
\begin{aligned}
& 2 \mathrm{H}_{2} \mathrm{O} \rightarrow 4 \mathrm{H}^{+}+\mathrm{O}_{2}+4 \mathrm{e} \\
& 4 \mathrm{OH}^{-} \rightarrow \mathrm{O}_{2}+2 \mathrm{H}_{2} \mathrm{O}+4 \mathrm{e} \\
& \text { No catodo: } \\
& 4 \mathrm{H}_{2} \mathrm{O}+4 \mathrm{e} \rightarrow 2 \mathrm{H}_{2}+4 \mathrm{OH}^{-} \\
& 4 \mathrm{H}^{+}+4 \mathrm{e}^{-} \rightarrow 2 \mathrm{H}_{2}
\end{aligned}
$$

A tensão elétrica é um dos parâmetros mais importantes na pintura cataforética, pois tensões elevadas conduzirão a um aumento de espessura de película depositada e a uma melhor penetração nas partes ocas das peças, além de permitir o aumento da velocidade da linha de produção, o que é desejado [4]. Porém, para cada tipo de tinta existe uma tensão máxima aplicável (tensão de ruptura), a partir da qual a película formada apresentará defeitos estruturais, como o mostrado na Figura 1, que irão afetar negativamente a proteção anticorrosiva. Por isso, geralmente as montadoras aplicam a tensão gradativamente, utilizando dois retificadores dentro dos tanques [5-7]. Outros fatores que devem ser considerados e que afetam o processo de pintura são a condutividade, $\mathrm{o} \mathrm{pH}$ e a temperatura do banho e a distância anodo-catodo [8].

\footnotetext{
* Contribuição técnica ao $69^{\circ}$ Congresso Anual da ABM - Internacional e ao 14ํㅡㄹ ENEMET - Encontro Nacional de Estudantes de Engenharia Metalúrgica, de Materiais e de Minas, 21 a 25 de julho de 2014, São Paulo, SP, Brasil.
} 


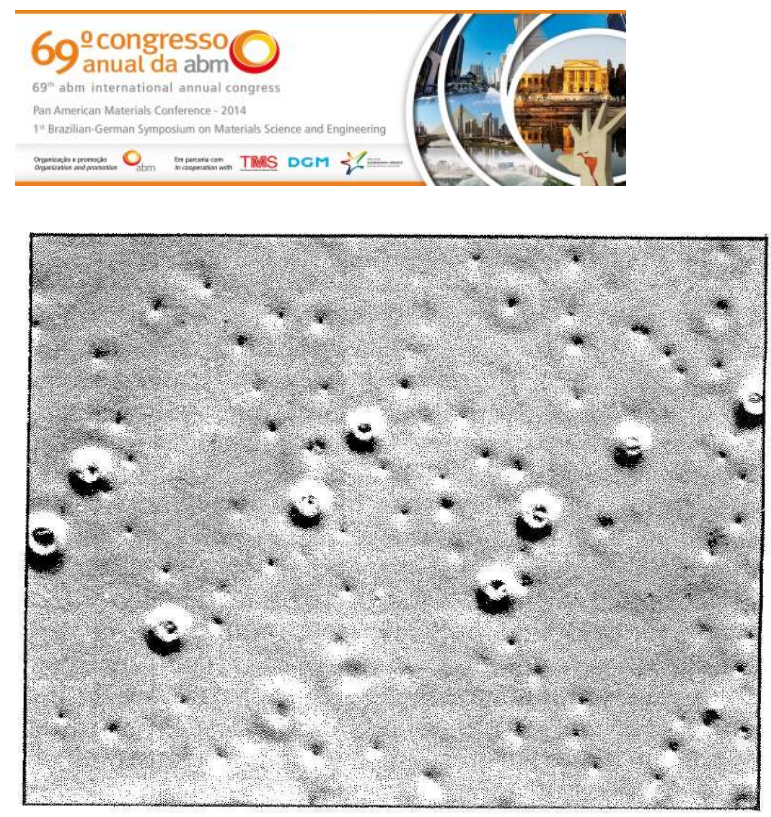

(a) Aspecto geral

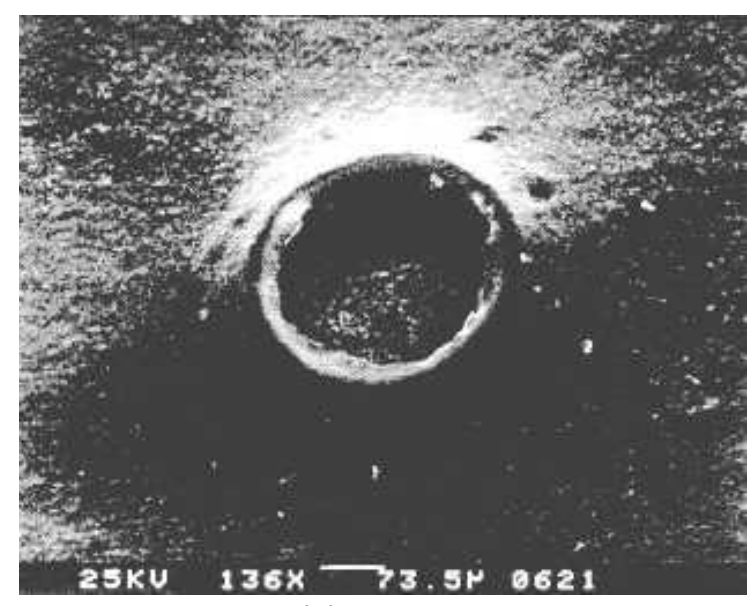

(b) Detalhe

Figura 1. Defeito cratera causado por excesso de hidrogênio [5].

Normalmente nos processos de pintura cataforética a primeira etapa é identificar a tensão de ruptura da película de tinta e, em seguida, a tensão máxima que pode ser aplicada sem que ocorram outros tipos de defeitos. Nesses experimentos é fixado o tempo mínimo e variados outros parâmetros importantes para o processo como, por exemplo, a distância anodo-catodo e a temperatura do banho, como mostrado na Figura 2 [9]. Entretanto, em uma linha industrial nem sempre é possível realizar essas alterações. Assim, abordagens dos tipos das tradicionalmente apresentadas na literatura podem não ser as mais convenientes na prática para assegurar uma película uniforme e sem defeitos como exige a indústria automobilística.

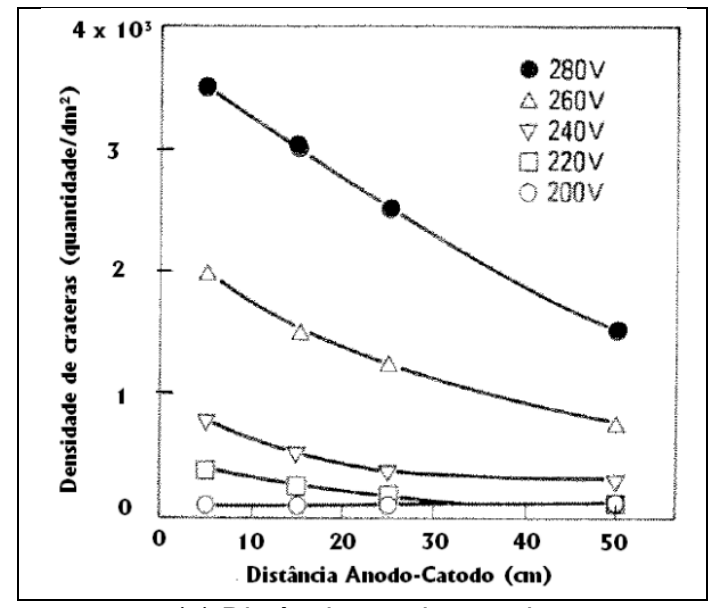

(a) Distância anodo-catodo

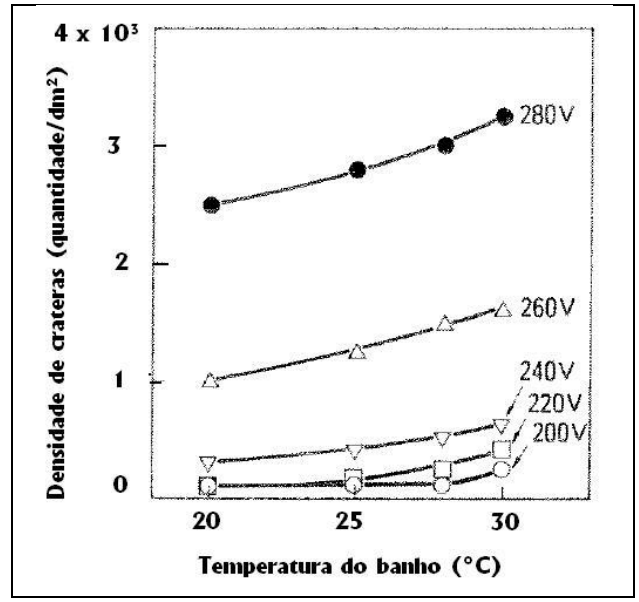

(b) Temperatura do banho

Figura 2. Densidade do defeito cratera em função da distância anodo-catodo, temperatura do banho da tinta e tensão [9].

Portanto, no presente trabalho foi desenvolvida uma metodologia para estabelecer "janelas de processamento de pintura cataforética" que não apenas proporcionem mais flexibilidade ao processo de pintura como também possam ser uma maneira conveniente de selecionar a tinta de melhor desempenho para um determinado processo, como mostrado esquematicamente na Figura 3. Nessa figura as condições mais restritivas para a pintura são as situadas próximas ao ponto 3 , ou seja, o dispêndio de muito tempo quando se aplica baixa tensão, o que não é conveniente para a produtividade.

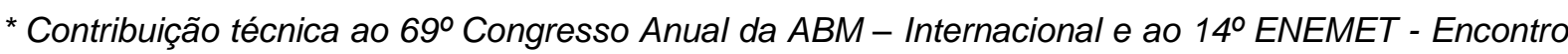
Nacional de Estudantes de Engenharia Metalúrgica, de Materiais e de Minas, 21 a 25 de julho de 2014, São Paulo, SP, Brasil.
} 

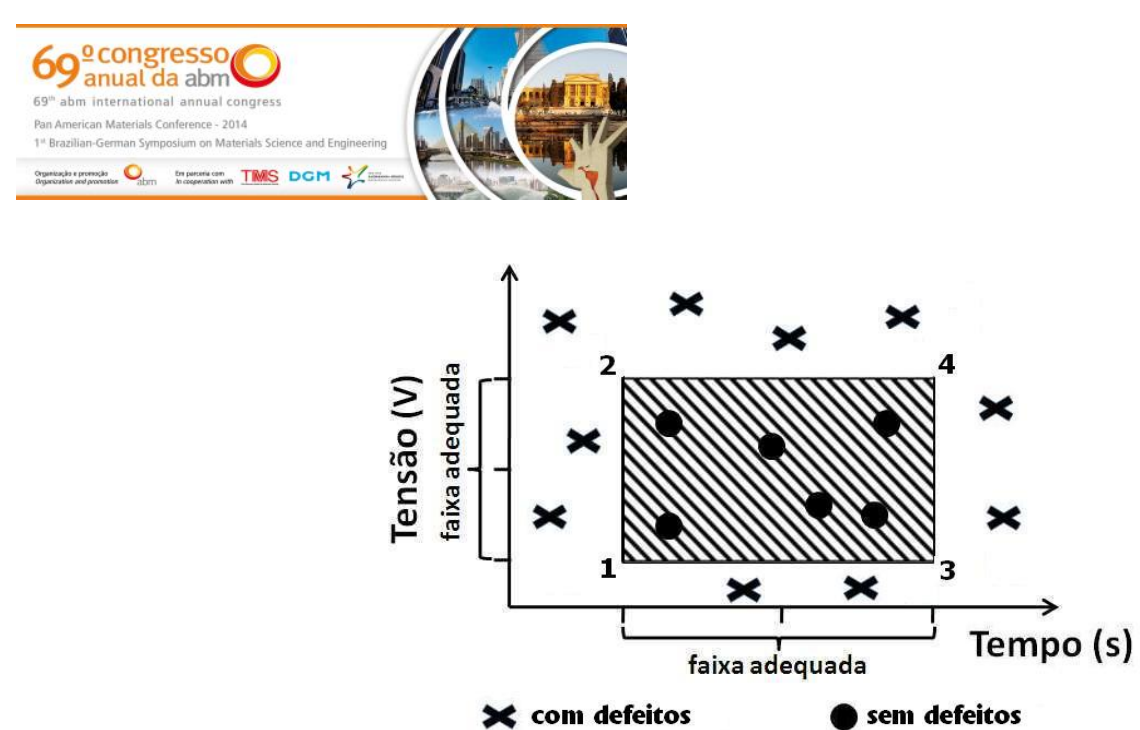

$\begin{array}{ll}1 \text { = menor tempo e menor tensão } & \mathbf{3}=\text { maior tempo e menor tensão } \\ \mathbf{2}=\text { menor tempo e maior tensão } & \mathbf{4}=\text { maior tempo e maior tensão }\end{array}$

Figura 3. Modelo esquemático de uma janela de processamento.

\section{MATERIAIS E MÉTODOS}

Para o desenvolvimento do trabalho foram selecionadas três tintas normalmente empregadas no mercado automobilístico, cujas principais informações dos seus boletins técnicos estão apresentadas na Tabela 1.

Tabela 1. Tintas utilizadas e suas respectivas condições de aplicação.

\begin{tabular}{c|c|c|c}
\hline Variáveis de Processo & Tinta 1 & Tinta 2 & Tinta 3 \\
\hline Temperatura do banho $\left({ }^{\circ} \mathrm{C}\right)$ & $28-34$ & $28-36$ & $30-35$ \\
\hline $\mathrm{pH}\left(25^{\circ} \mathrm{C}\right)$ & $5,6-5,9$ & $5,4-5,8$ & $5,7-6,2$ \\
\hline Condutividade $\left(\mu \mathrm{S} / \mathrm{cm} 25^{\circ} \mathrm{C}\right)$ & $1200-1600$ & $1300-1900$ & $1500-2000$ \\
\hline Teor de Sólidos $(\%)$ & $17-21$ & $17-23$ & $18-21$ \\
\hline Temperatura de cura $\left({ }^{\circ} \mathrm{C}\right)$ & $175 \pm 5$ & $175 \pm 5$ & $175 \pm 10$ \\
\hline Tempo de cura da tinta $(\mathrm{min})$ & 15 & 15 & 15 \\
\hline Espessura $(\mu \mathrm{m})$ & $17-22$ & $18-24$ & $17-23$ \\
\hline
\end{tabular}

As tintas foram aplicadas de acordo com as condições indicadas na Tabela 1. Nas etapas de pintura foram consideradas seis variáveis de processamento comuns em uma montadora: tensão 1, tempo 1 de rampa, tempo 1 de pintura, tensão 2, tempo 2 de rampa e tempo 2 de pintura, conforme diagrama esquemático da Figura 4.

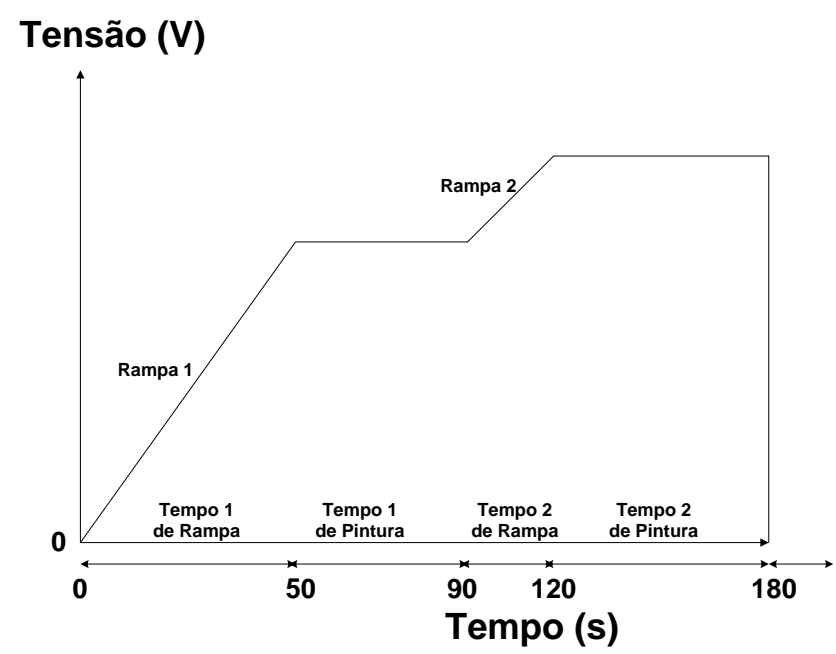

Figura 4. Diagrama esquemático ilustrando os tempos e tensões empregadas na pintura cataforética. Nesse exemplo: tempo 1 de rampa $=50 \mathrm{~s}$; tempo 1 de pintura $=40 \mathrm{~s}$; tempo 2 de rampa $=30 \mathrm{~s}$ e tempo 2 pintura $=60 \mathrm{~s}$.

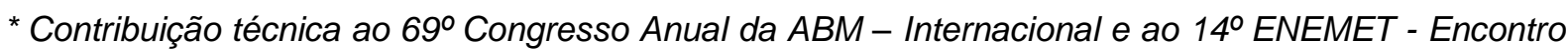
Nacional de Estudantes de Engenharia Metalúrgica, de Materiais e de Minas, 21 a 25 de julho de 2014, São Paulo, SP, Brasil.
} 


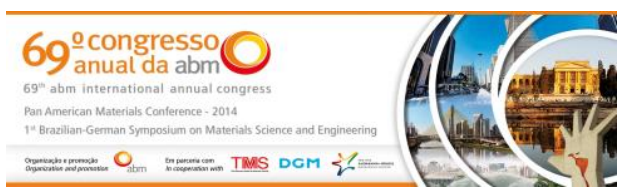

Foram utilizados quatro tipos de aços nos testes: sem revestimento de zinco (CC), galvanizado eletroliticamente (EG) e galvanizados a quente Gl (sem tratamento térmico da camada de zinco) e GA (com tratamento térmico da camada de zinco). Os galvanizados tinham a camada de zinco com massa de $60 \mathrm{~g} / \mathrm{m}^{2} / \mathrm{face}$. Todos aplicados em aços com qualidade apropriada para estampagem (intersticial free). Todos os corpos de prova foram desengraxados e fosfatizados conforme as etapas do diagrama esquemático apresentado da Figura 5.

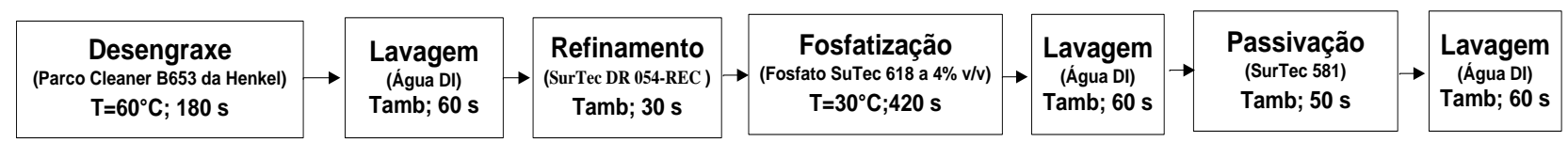

Figura 5. Diagrama esquemático do processo de pré-tratamento empregado antes da pintura.

Para o planejamento dos experimentos foi escolhida a Metodologia de Superfície de Resposta (MSR ou RSM-Response Surface Methodology) que é um conjunto de técnicas de planejamento e análise de experimentos usadas na modelagem matemática de respostas empregando-se o software comercial Statgraphics Plus for Windows Version 5.1.

Para a pintura dos corpos de prova foi montado um sistema utilizando-se um tanque de tinta, com capacidade para 15 litros, sob agitação e com trocador de calor, e 0 retificador de bancada CA/CC, da série ER-2000 $\mu \mathrm{PC}$, chaveado em alta frequência, microprocessado, com alimentação de $220 \mathrm{~V}$ ca/monofásica $/ 60 \mathrm{~Hz}$, com saída de 0 a $400 \mathrm{Vcc} / 5 \mathrm{~A}$ e que permite o emprego de 2 níveis de tensão de operação.

A temperatura foi controlada por meio de um trocador de calor de modo que sua variação fosse a mínima possível em relação à informada nos boletins técnicos das tintas.

Nas avaliações do pH foi utilizado um pHmetro digital que tem o eletrodo combinado de $\mathrm{pH}$ com junta esmerilhada (com anel de vidro que facilita a limpeza e mantêm 0 diafragma de leitura sem impurezas) e diafragma anular para tintas. Para ajuste do $\mathrm{pH}$ dos banhos existia a possibilidade de se utilizar solução ácido sulfâmico $10 \%$, contudo, não foi necessário realizar ajustes durante os testes.

A condutividade foi medida durante os testes utilizando-se um condutivímetro digital composto por célula de condutividade de inox para tintas com termo acoplado.

Os sólidos são substâncias não voláteis na composição da tinta, ou seja, são os componentes da tinta que após a sua secagem não evaporam e constituem o filme seco. Para sua avaliação, foi pesado $1,0 \mathrm{~g} \pm 0,2 \mathrm{~g}$ do banho de tinta em um recipiente de alumínio, que foi mantido em estufa com circulação de ar por 1 hora a $130^{\circ} \mathrm{C}$. Após esse tempo, o recipiente com o resíduo sólido foi pesado e a diferença entre os pesos inicial e o final dividido pelo peso inicial determinou o teor de sólidos na tinta.

Após a pintura, os corpos de prova foram colocados em estufa com recirculação forçada de ar nas temperaturas e tempos indicados nos boletins técnicos para que ocorresse a cura (polimerização) das tintas.

A espessura da película seca de tinta foi medida utilizando-se o medidor por indução magnética Fischerscope MMS (Multi Measuring System).

\section{RESULTADOS E DISCUSSÃO}

Na Tabela 1 do anexo são apresentadas as condições empregadas para a obtenção da janela de processamento, por exemplo, para pintura do aço não revestido

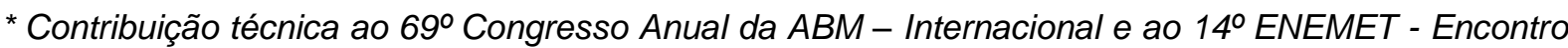
Nacional de Estudantes de Engenharia Metalúrgica, de Materiais e de Minas, 21 a 25 de julho de 2014, São Paulo, SP, Brasil.
} 
7 Mantagne JM, Houziel J. Pinholing mechanisms during cataphoretic painting of galvannealed steel sheet. In: Proceedings of the 4 International Conference on Zinc and Zinc Alloy Coated Steel Sheet (GALVATECH'98); 1998; Chiba, Japan. The Iron and Steel Institute of Japan; 1998. p.697-702.

8 Brewer GEF, Hamilton CC, Honsch ME. The influence of certain parameters on throwing power. Journal of paint technology. 1969;41(529).

9 Kitayama M, Azami T, Miura N, Ogasawara T. Cratering in electrodeposition coating of cationic paint on galvannealed steel sheet. Trans. Iron Steel Inst. Jpn. 1984;24(9):742750.

\section{ANEXO}

Tabela 1. Condições de Aplicação da Tinta 1 no Aço Não Revestido

\begin{tabular}{|c|c|c|c|c|c|c|c|c|}
\hline Teste & $\begin{array}{c}\text { Tensão } \\
1(\mathrm{~V})\end{array}$ & $\begin{array}{c}\text { Rampa } \\
1 \text { (s) }\end{array}$ & $\begin{array}{c}\text { Tempo } \\
1 \text { (s) }\end{array}$ & $\begin{array}{c}\text { Tensão } \\
2(\mathrm{~V})\end{array}$ & $\begin{array}{c}\text { Rampa } \\
2 \text { (s) }\end{array}$ & $\begin{array}{c}\text { Tempo } \\
2 \text { (s) }\end{array}$ & $\begin{array}{c}\text { Espessura } \\
\text { da tinta } \\
(\mu \mathrm{m})\end{array}$ & $\begin{array}{c}\text { Conforme? } \\
\text { [1] }\end{array}$ \\
\hline 1 & 190 & 20 & 15 & 210 & 5 & 140 & 15,4 & Não \\
\hline 2 & 190 & 20 & 15 & 240 & 10 & 140 & 16,9 & Não \\
\hline 3 & 190 & 20 & 15 & 240 & 10 & 140 & 16,9 & Não \\
\hline 4 & 190 & 40 & 15 & 210 & 10 & 260 & 26,7 & Não \\
\hline 5 & 190 & 40 & 15 & 210 & 10 & 260 & 26,7 & Não \\
\hline 6 & 190 & 40 & 15 & 210 & 10 & 190 & 27,9 & Não \\
\hline 7 & 190 & 40 & 15 & 210 & 10 & 115 & 17,0 & ponto 3 \\
\hline 8 & 190 & 40 & 15 & 210 & 10 & 115 & 16,9 & ponto 3 \\
\hline 9 & 190 & 20 & 15 & 210 & 10 & 140 & 19,8 & Não \\
\hline 10 & 245 & 50 & 15 & 270 & 10 & 105 & 17,5 & Não \\
\hline 11 & 245 & 50 & 15 & 270 & 10 & 245 & 32,6 & Não \\
\hline 12 & 245 & 50 & 15 & 270 & 10 & 175 & 28,9 & Não \\
\hline 13 & 245 & 50 & 15 & 270 & 10 & 105 & 23,4 & ponto 4 \\
\hline 14 & 245 & 50 & 15 & 270 & 10 & 105 & 20,2 & ponto 4 \\
\hline 15 & 260 & 25 & 15 & 320 & 12 & 30 & 13,7 & Não \\
\hline 16 & 320 & 60 & 15 & 340 & 10 & 50 & 18,7 & Não \\
\hline 17 & 320 & 60 & 15 & 340 & 10 & 50 & 19,0 & Não \\
\hline 18 & 320 & 60 & 15 & 340 & 10 & 130 & 32,1 & Não \\
\hline 19 & 320 & 60 & 15 & 340 & 10 & 130 & 31,8 & Não \\
\hline 20 & 320 & 60 & 15 & 340 & 10 & 65 & 28,3 & Não \\
\hline 21 & 320 & 60 & 5 & 340 & 5 & 65 & 26,5 & Não \\
\hline 22 & 300 & 60 & 15 & 320 & 10 & 65 & 22,5 & ponto 2 \\
\hline 23 & 300 & 60 & 15 & 320 & 10 & 65 & 23,7 & ponto 2 \\
\hline 24 & 245 & 25 & 15 & 270 & 5 & 36 & 12,1 & Não \\
\hline 25 & 245 & 50 & 15 & 270 & 10 & 65 & 13,6 & Não \\
\hline 26 & 245 & 50 & 15 & 270 & 10 & 65 & 14,2 & Não \\
\hline 27 & 260 & 50 & 15 & 270 & 10 & 143 & 28,3 & Não \\
\hline 28 & 260 & 50 & 15 & 270 & 10 & 75 & 22,9 & Não \\
\hline 29 & 245 & 50 & 15 & 260 & 10 & 75 & 16,9 & ponto 1 \\
\hline 30 & 245 & 50 & 15 & 260 & 10 & 75 & 16,6 & ponto 1 \\
\hline
\end{tabular}

Obs. Os pontos em negrito nessa tabela foram aqueles utilizados para construção da janela de processamento do aço não revestido quando utilizou-se a Tinta 1 [1]. Conforme significa sem ruptura, sem defeitos estruturais e com a espessura da película seca de tinta de acordo com o seu boletim técnico.

\footnotetext{
* Contribuição técnica ao 69ำ Congresso Anual da ABM - Internacional e ao 14ํㅡㄹ ENEMET - Encontro Nacional de Estudantes de Engenharia Metalúrgica, de Materiais e de Minas, 21 a 25 de julho de 2014, São Paulo, SP, Brasil.
} 